\title{
Effect of Thickness on Magnetic Dipolar and Exchange Interactions in SmCo/FeCo/SmCo Thin Films
}

\author{
Carlos Iván Rodríguez Rodríguez ${ }^{1,2}$, José Rurik Farías Mancillaํㅜ, Karla Edith Vega Chavez², \\ Francisco Espinosa Magaña ${ }^{3}$, Sion Federico Olive Méndez ${ }^{3}$, \\ José Trinidad Elizalde Galindo ${ }^{1}$ \\ ${ }^{1}$ Instituto de Ingeniería y Tecnología, Universidad Autónoma de Ciudad Juárez, Ciudad Juárez, México \\ ${ }^{2}$ Universidad Tecnológica de Ciudad Juárez, Ciudad Juárez, México \\ ${ }^{3}$ Centro de Investigación de Materiales Avanzados (CIMAV), Chihuahua, México \\ Email: carlos rodriguez@utcj.edu.mx
}

Received 10 June 2015; accepted 1 September 2015; published 4 September 2015

Copyright (C) 2015 by authors and Scientific Research Publishing Inc.

This work is licensed under the Creative Commons Attribution International License (CC BY). http://creativecommons.org/licenses/by/4.0/

(c) (i) Open Access

\section{Abstract}

SmCo/FeCo/SmCo trilayer was deposited with two different thickness configurations for soft phase (FeCo); $50 \mathrm{~nm} / 10 \mathrm{~nm} / 50 \mathrm{~nm}$ and $50 \mathrm{~nm} / 25 \mathrm{~nm} / 50 \mathrm{~nm}$ were deposited on Si (111) substrate and Ta (50 nm) seed layer by RF magnetron sputtering in a pressure, p, of $30-35 \mathrm{~m}$ Torr. After deposition the films were annealed under Ar atmosphere at temperature T equal to 923 and 973 for different times followed by quenching in water. X-ray diffraction patterns were obtained to identified phase presents and calculate average crystallite size. To study the effect of configuration thickness in soft phases, DC magnetic measurements were carried out; the measurements were done in the temperature interval of 300 - $50 \mathrm{~K}$. Hysteresis loops collected at low temperatures exposed an increment in coercivity with the decrease of $T$ and at same time, presented a "knee" in the second quadrant of the demagnetization curve, which suggests that the inter-layer exchange coupling becomes less effective, being more evident for sample with $50 \mathrm{~nm} / 25 \mathrm{~nm} / 50$ $\mathrm{nm}$ thickness. Moreover, $\delta M(\mathrm{H})$ plots were calculated from magnetic measurements at three different temperatures, T, equal to 300,150 and $50 \mathrm{~K}$, which corroborates that the dipolar interactions became stronger when thickness of soft phases increases. Finally, the thickness effect is attributed to the $\mathrm{SmCo}_{5}$ phase magnetocrystalline anisotropy constant, which is responsible for the exchange coupling length.

\section{Keywords}

Exchange Interactions, Dipolar Interaction, Anisotropy

How to cite this paper: Rodríguez, C.I.R., Mancilla, J.R.F., Chavez, K.E.V., Magaña, F.E., Méndez, S.F.O. and Galindo, J.T.E. (2015) Effect of Thickness on Magnetic Dipolar and Exchange Interactions in SmCo/FeCo/SmCo Thin Films. Advances in Materials Physics and Chemistry, 5, 368-373. http://dx.doi.org/10.4236/ampc.2015.59037 


\section{Introduction}

Kneller and Hawig [1] first introduce an exchange spring composite magnet consisted of hard and soft magnets. The hard magnetic phase provides a high coercive force while the soft phase offers a high magnetization. Then, Skomski and Coey [2] predicted a giant energy product $(\mathrm{BH})_{\max }$ with theoretical value of 120 MGOe using this exchange spring. Since the magnetic properties and the degree of exchange coupling are strongly dependent on the microstructural parameters, phase distribution, volume and crystallite size. The nanocomposite multilayer films can be prepared by the technique such melt spinning [3]-[5], mechanical milling [6]-[8], sputtering [9]-[12] and nanoparticle assembly [13]. Nanocomposite multilayer films prepared by sputtering are of the state of the art in permanent magnets and, its interest is not only for understanding the mechanism of nanocomposite magnets but also for developing the next generation of magnets [14].

For the last two decades, many researchers focused their research on the exchange coupling in the interface between the hard and soft phases [15], the temperature dependence of the exchange spring bilayers, the effect of inter-diffusion at the interface on exchange coupling and the effect of controlled composition interface on exchange spring magnet [16]-[22].

In this paper, we report the study of effect thickness in magnetic dipolar and exchange interaction in the trilayer $\mathrm{SmCo} / \mathrm{FeCo} / \mathrm{SmCo}$. It was found a strong dependence of soft layer thickness in the exchange and dipolar interactions at low temperature measurements.

\section{Experimental}

SmCo/FeCo/SmCo thin films were deposited on Si (100) substrate by RF magnetron sputtering system with a base pressure of $5 \times 10^{-6}$ Torr. SmCo and FeCo were deposited by SmCo target composition and FeCo target composition. A Ta underlayer and Ta cap layer also were deposited by RF magnetron sputtering Ta target (purity of 99.95\%). Ar pressure was kept at range of 30 - 35 m Torr. Two different thickness configurations for soft phase (FeCo): $50 \mathrm{~nm} / 10 \mathrm{~nm} / 50 \mathrm{~nm}$ and $50 \mathrm{~nm} / 25 \mathrm{~nm} / 50 \mathrm{~nm}$ were deposited; the thickness of Ta, SmCo and FeCo layer were controller by Inficon microbalance. The as-deposited film were annealed in vacuum at different temperature $\mathrm{T}$ equal to $923 \mathrm{~K}$ for $60 \mathrm{~min}$ and $973 \mathrm{~K}$ for $15 \mathrm{~min}$ followed by quenching in water. X-ray diffraction (XRD) patterns were obtained using a Panalytical X'Pert MPD diffractometer with Cu-K $\alpha$ radiation in a $2 \theta$ ranging from $30^{\circ}-60^{\circ}$ with a step size of $0.008^{\circ}$ and time for step $30 \mathrm{~s}$. Magnetic hysteresis loops were measured on a Quantum Design VersaLab vibrating sample magnetometer (VSM) in fields up to 30 kOe at temperature, $\mathrm{T}$, ranging from 300 to $50 \mathrm{~K}$.

\section{Results and Discussion}

Figure 1 shows XRD pattern obtained for thickness variation in the soft phase from 10 to $25 \mathrm{~nm}$ and annealing temperature from $923 \mathrm{~K}$ for 60 minutes to $973 \mathrm{~K}$ for 30 minutes, respectively. To understand the magnetic behavior of multilayer system just FeCo soft layer thickness changed, SmCo hard layer thickness was constant to $50 \mathrm{~nm}$. In DRX SmCo and FeCo diffraction peaks are very small due the formation of most SmCo and FeCo clusters were amorphous associated with few small crystallites [23]. All phases in samples were identified with $\mathrm{SmCo}_{5}$ (PDF2-00-027-1122), $\mathrm{Fe}_{65} \mathrm{Co}_{35}$ (PDF2-00-048-1817), Ta (PDF2-00-002-1104), TaO 2 (PDF2-00-0191297), $\mathrm{Ta}_{2} \mathrm{O}_{5}$ (PDF2-00-018-1304). The as-deposited sample was amorphous. Therefore, it is evident that as heat treatment was carried out, the (111) peak of the $\mathrm{SmCo}_{5}$ appears and also the (110) peak of $\mathrm{Fe}_{65} \mathrm{Co}_{35}$.

The $\mathrm{M}-\mathrm{H}$ loops of $\mathrm{SmCo} / \mathrm{FeCo} / \mathrm{SmCo}$ samples annealed at $\mathrm{T}=923 \mathrm{~K}$ for 60 minutes and $\mathrm{T}=973 \mathrm{~K}$ for 30 minutes were measurement by VSM with a magnetic field of $30 \mathrm{kOe}$ applied in substrate plane direction. Figure 2 shows the hysteresis loops of $\mathrm{SmCo} / \mathrm{FeCo} / \mathrm{SmCo}$ films with different thickness for soft phase, annealed at different temperature. Samples annealed at $973 \mathrm{~K}$ for 30 minutes and $923 \mathrm{~K}$ for 60 minutes were deposited with 10 and $25 \mathrm{~nm}$ for FeCo layer, respectively. The VSM measurement temperature was in the range between 300 and $50 \mathrm{~K}$. The demagnetization curve at $300 \mathrm{~K}$ has a smooth convex profile that, according to Kneller and Hawig, correspond to a fully exchange coupled nanocomposite. Meanwhile, as temperature decrease, the sample with FeCo layer with $10 \mathrm{~nm}$ thickness exhibits a little "Knee” in the second quadrant and the "Knee" for sample with FeCo layer with $25 \mathrm{~nm}$ thickness is much more pronounced. This effect has been interpreted as an exchange decoupling due to the difference in the thickness of FeCo layer [23] [24]. 


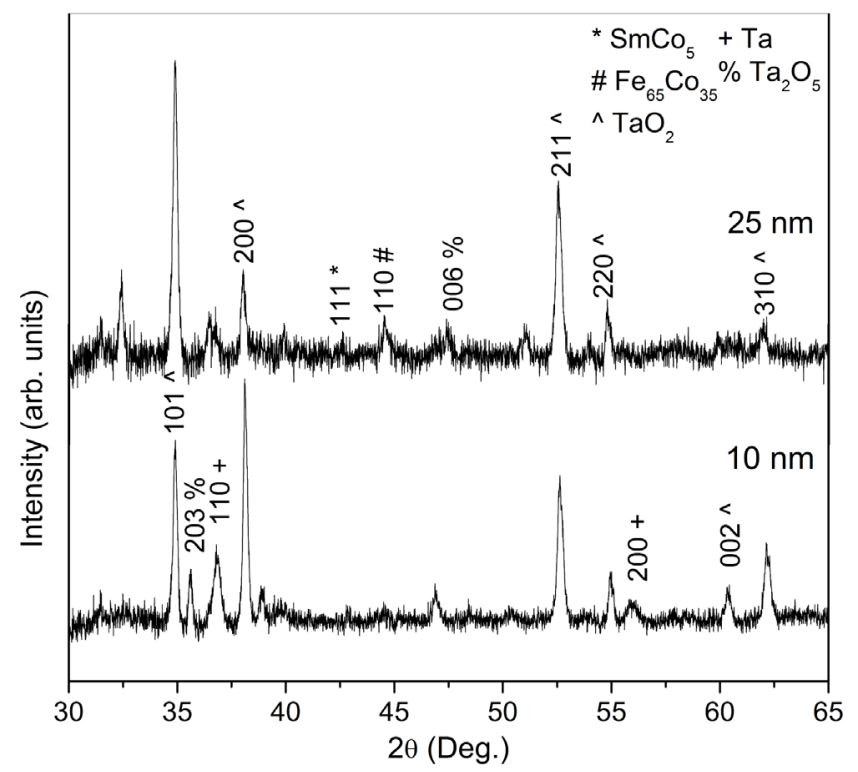

Figure 1. XRD of SmCo/FeCo/SmCo films with different thickness and heat treatment.

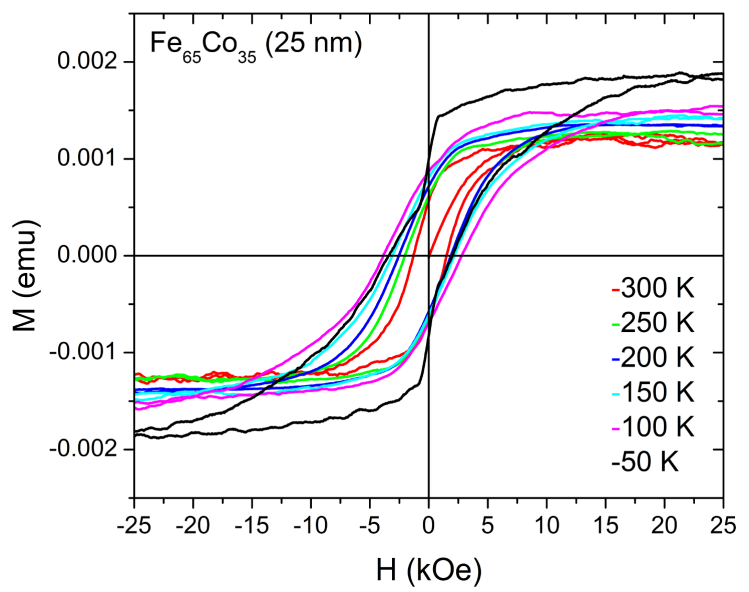

(a)

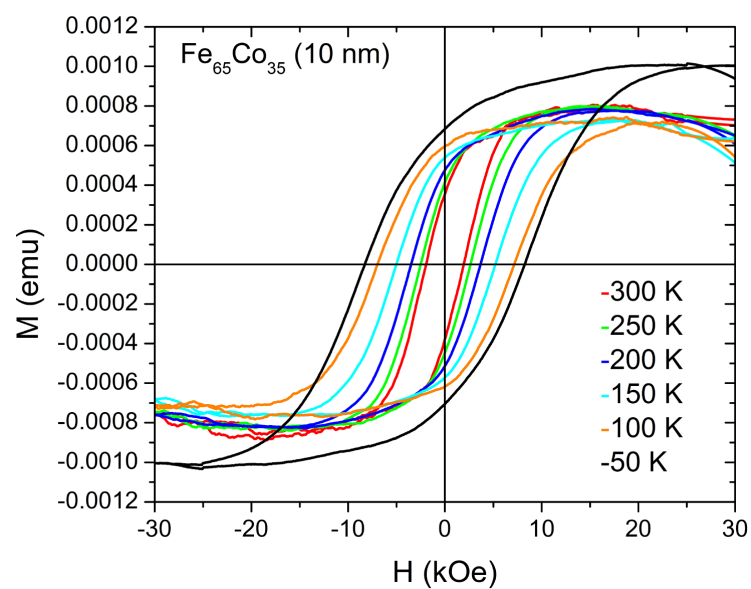

(b)

Figure 2. Hysteresis loop of $\mathrm{SmCo} / \mathrm{FeCo} / \mathrm{SmCo}$ films measured in low temperature range $\mathrm{T}=300-50 \mathrm{~K}$.

Figure 3 shows maximum magnetization, $\mathrm{M}_{\mathrm{r}}$, remanence, and $\mathrm{M}_{\max }$, remanence to maximum magnetization ratio, $\mathrm{M}_{\mathrm{r}} / \mathrm{M}_{\max }$, and coercivity, $\mathrm{H}_{\mathrm{C}}$, behavior of $\mathrm{SmCo} / \mathrm{FeCo} / \mathrm{SmCo}$ films samples annealed at $\mathrm{T}=923 \mathrm{~K}$ for 60 minutes and $\mathrm{T}=973 \mathrm{~K}$ for 30 minutes. The measurement temperature was in the range between 300 and $50 \mathrm{~K}$. For soft layer thickness of $10 \mathrm{~nm}$ the $\mathrm{M}_{\max }$ and $\mathrm{M}_{\mathrm{r}}$ shows a little increment upon cooling besides $\mathrm{H}_{\mathrm{C}}$ increase by more than $400 \%$ when temperature is lowered to $50 \mathrm{~K}$. This behavior can be attributed to the exchange coupling present because the hard layer. Besides, for soft layer thickness of $25 \mathrm{~nm}, \mathrm{M}_{\max }$ and $\mathrm{M}_{\mathrm{r}}$ shows a similar behavior but for lower temperature, $50 \mathrm{~K}$, a significant decoupling between both phases, soft and hard, can be expected because the "knee" appearing in the second and four quadrant close to cero applied field. This behavior is attributed to the dipolar interaction present because the soft layer thickness.

$\delta \mathrm{M}$ curves were calculated to determine the behavior of thin films system when the soft layer thickness changes. Below we describe, how these curves have the potential to yield information about the magnetic interactions in two-phase magnetic nanocomposites.

$\delta \mathrm{M}$ plots are defined starting from the observation that an assembly of uniaxial magnetically-noninteraction single-domain particles obeys the relationship: 


$$
M_{d}\left(H_{m}\right)=M_{r}-2 M_{r}\left(H_{m}\right)
$$

where $M_{r}\left(H_{m}\right)$ is acquired after the application and subsequent removal of a directly applied field $H_{\text {max }}$, and $M_{d}\left(H_{m}\right)$ is the direct current demagnetization remanence measured after applying the maximum positive magnetic field $H_{\max }$ (starting from the demagnetized state), and then applying and removing a negative magnetic field $-H_{m}$ on the demagnetization curve $M_{r}$ is the maximum remanent magnetization measured after applying the maximum magnetic field [26]. If magnetic interactions are present, the deviation of $M_{d}\left(H_{m}\right)$ from $M_{r}-$ $2 M_{r}\left(H_{n}\right)$ normalized to the maximum remanence:

$$
\delta M \equiv\left\{M_{d}\left(H_{m}\right)-\left[M_{r}-2 M_{r}\left(H_{m}\right)\right]\right\} / M_{r}
$$

Is a measure such interactions, and in particular, can be used to study the interplay between the exchange and the dipolar interactions in nanocomposite magnets [25]. Positive $\delta M$ values are interpreted as magnetizing short-range exchange interactions, whereas negative $\delta M$ values correspond to dipolar interaction [25]. Three temperatures were choose to calculate curves, in the lower temperature the observed effect of decoupling was more significant. In Figure 4, $\delta M$ plots shows the effect of soft layer thickness as measurement temperature is decreasing. $\delta M$ curve at 300 and $150 \mathrm{~K}$, for sample with FeCo layer with $10 \mathrm{~nm}$ thickness presents a positive peak around 2 and $5 \mathrm{kOe}$, apositive peak indicates an exchange interaction coupling; for $\delta M$ curve at $50 \mathrm{~K}$, is

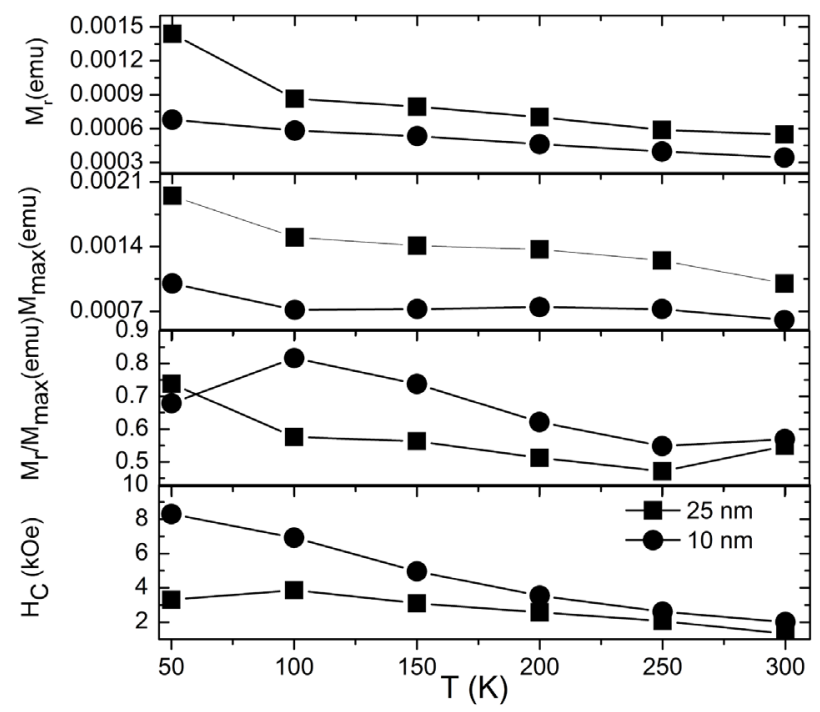

Figure 3. Magnetic properties behavior of $\mathrm{SmCo} / \mathrm{FeCo} / \mathrm{SmCo}$ films with different soft phase thickness $10 \mathrm{and} 25 \mathrm{~nm}$.

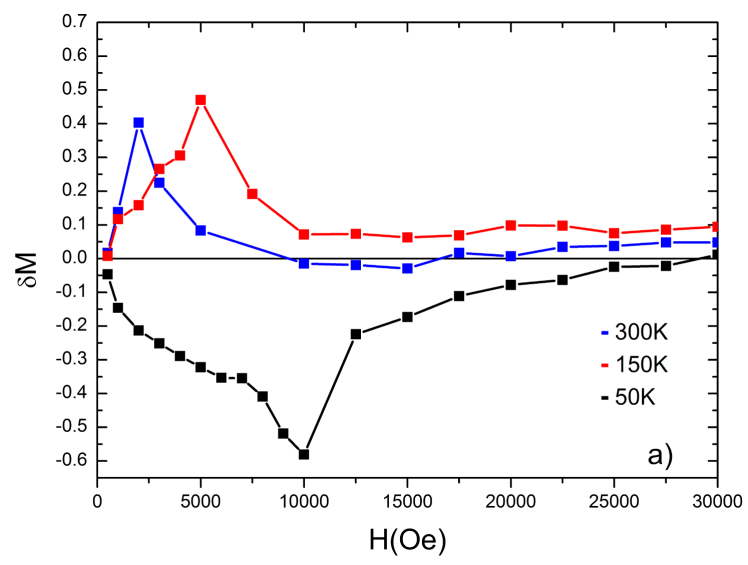

(a)

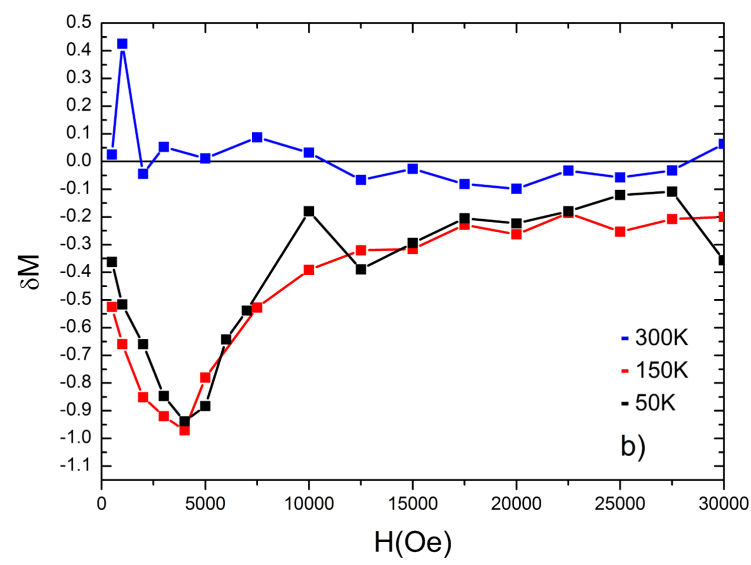

(b)

Figure 4. $\delta M$ curves of $\mathrm{SmCo} / \mathrm{FeCo} / \mathrm{SmCo}$ films with different thickness (a) $10 \mathrm{~nm}$ and (b) $25 \mathrm{~nm}$ for FeCo phase. 
observed a peak in the negative side, this mean a dipolar interaction is occurring but exchange coupling is stronger than dipolar interaction. Meanwhile, $\delta M$ curve at $300 \mathrm{~K}$, for sample FeCo layer with $25 \mathrm{~nm}$ thickness, present a peak in the positive side, on the other hand $\delta M$ curve at 150 and $50 \mathrm{~K}$, present a peak in the negative side, this mean the dipolar interaction is stronger than exchange interaction, that means $\mathrm{SmCo} / \mathrm{FeCo} / \mathrm{SmCo}$ are decouple when soft thickness layer increase and $\mathrm{T}$ decrease.

\section{Conclusion}

The magnetic properties were affected when the thickness of soft phase varies. The SmCo/FeCo/SmCo were deposited for two thickness, 10 and $25 \mathrm{~nm}$, and annealed at different temperature. It was found that characteristic "knee" observed in the second quadrant demagnetizing curve is exposing the exchange decoupling between interlayers. The exchange decoupling occurs when soft thickness layer is increasing. Our study clarified how the exchange interactions decrease at low temperature as was expected because of the magnetocrystalline anisotropy dependence on it.

\section{Acknowledgements}

The authors want to thank to UACJ for the support to carry out this research and the Laboratorio Nacional de Nanotecnología from CIMAV for the studies. This research was supported by SEP-CONACYT project number 084602 .

\section{References}

[1] Kneller, E.F. and Hawig, R. (1991) The Exchange-Spring Magnet: A New Material Principle for Permanent Magnets. IEEE Transactions on Magnetics, 27, 3588-3600.

[2] Skomski, R. and Coey, J.M.D. (1993) Giant Energy Product in Nanostructured Two-Phase Magnets. Physical Review $B, 48,15812-15816$.

[3] Coehoorn, R., Mooij, D.B. and Deward, C. (1989) Meltspun Permanent Magnete Materials Containing $\mathrm{Fe}_{3} \mathrm{~B}$ as the Main Phase. Journal of Magnetism and Magnetic Materials, 80, 101-104. http://dx.doi.org/10.1016/0304-8853(89)90333-8

[4] Kobayashi, T., Yamasaki, M. and Hamano, M. (2000) Mössbauer Study on Intergranular Phases in the bcc-Fe/NdFeB Nanocomposite Alloys. Journal of Applied Physics, 87, 6579-6581. http://dx.doi.org/10.1063/1.372776

[5] Cheng, Z.H., Kronmüller, H. and Shen, B.G. (1998) Microestructure Refinement and Improvements of Magnetic Properties of Two-Phase Exchange-Coupled $\mathrm{Sm}_{2} \mathrm{Fe}_{15} \mathrm{Ga}_{2} \mathrm{C}_{\mathrm{x}} / \alpha$-Fe Nanocomposite by Additional Zr. Applied Physics Letter, 73, 1586-1588. http://dx.doi.org/10.1063/1.122212

[6] Gomg, W., Hadjipanayis, G.C. and Krause, R.F. (1994) Mechanically Alloyed Nanocomposite Magnets. Journal of Applied Physics, 75, 6649-665.

[7] Kanekiyo, H. and Hirosawa, S. (1998) Thick $\mathrm{Fe}_{3} \mathrm{~B} / \mathrm{Nd}_{2} \mathrm{Fe}_{14} \mathrm{~B}$ Nanocomposite Permanent Magnet Flakes Prepared by Slow Quenching. Journal Applied Physics, 83, 6265-6267.

[8] Zhang, J., Zhang, S.Y., Zhang, H.W. and Shen, B.C. (2001) Structure, Magnetic Properties, and Coercivity Mechanism of Nanocomposite $\mathrm{SmCo}_{5} / \alpha$-Fe Magnets Prepared by Mechanical Milling. Journal of Applied Physics, 89, 5601-5605.

[9] Fullerton, E.E., Jiang, J.S., Sowers, C.H., Pearson, J.E. and Bader, J.D. (1998) Structure and Magnetic Properties of Exchange-Spring Sm-Co/Co Superlattices. Applied Physics Letters, 72, 380-382.

[10] Liu, J.P., Lou, C.P., Liu, Y. and Sellmyer, D.J. (1998) High Energy Products in Rapidly Annealed Nanoscale Fe/Pt Multilayers. Applied Physics Letter, 72, 483-485.

[11] Zhang, J., Takahashi, Y.K., Gopalan, R. and Hono, K. (2005) Sm(Co, Cu) 5 /Fe Exchange Spring Multilayer Films with High Energy Product. Applied Physics Letters, 86, Article ID: 122509. http://dx.doi.org/10.1063/1.1889238

[12] Liu, W., Zhang, Z.D., Liu, J.D., Chen, L.J., He, L.L., Lui, Y., Sun, X.K. and Sellmyer, D.J. (2002) Exchange Coupling and Remanence Enhanced in Nanocomposite Multilayer Magnets. Advanced Materials, 14, 1832-1834. http://dx.doi.org/10.1002/adma.200290012

[13] Zeng, H., Li, J., Liu, J.P., Wang, Z.L. and Sun, S.H. (2002) Exchange-Coupled Nanocomposite Magnets via Nanoparticle Self-Assembly. Nature, 420, 395-398. http://dx.doi.org/10.1038/nature01208

[14] Zhang, J., Li, Y.X., Wang, F., Shen, B.G. and Sun, J.R. (2010) Coercivity Mechanism of Nanocomposite Sm-Co/Fe Multilayer Films. Journal of Applied Physics, 107, Article ID: 043911. http://dx.doi.org/10.1063/1.3309772

[15] Ghidini, M., Asti, G., Pellicelli, R., Pernechele, C. and Solzi, M. (2007) Hard-Soft Magnets. Journal of Magnetism and 
Magnetic Materials, 316, 159-165.

[16] Rong, C., Liu, Y. and Liu, J.P. (2008) Do Thermal Fluctuations Influence the Recoil Loops of Nanocomposite Magnets? Applied Physics Letter, 93, Article ID: 042508. http://dx.doi.org/10.1063/1.2956392

[17] Rong, C.B. and Liu, J.P. (2009) Effect of Thermal Fluctuation on the Recoil Loops of SmCo $/$ Fe Nanocomposite System. Journal of Applied Physics, 105, Article ID: 07A714. http://dx.doi.org/10.1063/1.3067850

[18] Choi, Y., Jiang, J.S., Ding, Y., Rosenberg, R.A., Pearson, J.E., Bader, S.D., Zambano, A., Murakami, M., Takeuchi, I., Wang, Z.L. and Liu, J.P. (2007) Role of Diffused Co Atoms in Improving Effective Exchange Coupling Sm-CO/Fe Spring Magnets. Physical Review B, 75, Article ID: 104432. http://dx.doi.org/10.1103/PhysRevB.75.104432

[19] Liu, Y., Wu, Y.Q., Kramer, M.J., Choi, Y. and Jiang, J.S. (2008) Microstructure Analysis of a SmCo/Fe Exchange Spring Bilayer. Applied Physics Letters, 93, Article ID: 192502. http://dx.doi.org/10.1063/1.2978325

[20] Liu, Y., TeVelthuis, S.G.E., Kiang, J.S., Choi, Y., Bader, S.D., Parizzi, A.A., Ambaye, H. and Lauter, V. (2011) Magnetic Structure in Fe/Sm-Co Exchange Spring Bilayers with Intermixed Interfaces. Physical Review B, 83, Article ID: 174418. http://dx.doi.org/10.1103/PhysRevB.83.174418

[21] Choi, Y., Jiang, J.S., Pearson, J.E., Bader, S.D. and Kavich, J.J. (2007) Controlled Interface Profile in Sm-Co/Fe Exchange-Spring Magnets. Applied Physics Letters, 91, Article ID: 072509. http://dx.doi.org/10.1063/1.2769755

[22] Sankar, S.G., Rao, V.U.S., Segal, E., Wallace, W.E., Frederick, W.G.D. and Garret, H.J. (1925) Magnetocrystalline Anisotropy of $\mathrm{SmCo}_{5}$ and Its Interpretation on Crystal-Field Model. Physical Review B, 11, 435-439. http://dx.doi.org/10.1103/PhysRevB.11.435

[23] Li, N., Li, B.H., Feng, C., Li, M.H. and Yu, G.H. (2012) Effect of Film Thickness on Magnetic Properties of Cr/SmCo/ Cr Films. Journal of Rare Earths, 30, 446-449. http://dx.doi.org/10.1016/S1002-0721(12)60070-2

[24] Elizalde Galindo, J.T., Bhuiya, A.W., Rivera Gomez, F., Matutes Aquino, J.A. and Botez, C.E. (2008) Temperature Dependence of Magnetic Properties and Magnetic Interactions in $\mathrm{YCo}_{5} / \mathrm{Y}_{2} \mathrm{Co}_{17}$ Nanocomposite Powders. Journal Applied Physics, 41, Article ID: 095008.

[25] Elizalde Galindo, J.T., Botez, C.E., Rivera Gómez, F. and Matutes Aquino, J.A. (2007) Annealing Dependence of Magnetic Interactions in $\mathrm{YCo}_{5}(70 \% w t)+\mathrm{Y}_{2} \mathrm{Co}_{17}(30 \% w t)$ Nanocomposite Powders. Physics Letters A, 336, 110-113. http://dx.doi.org/10.1016/j.physleta.2007.01.063

[26] Wohlfarth, E.P. (1958) Relations between Different Modes of Acquisition of the Remanent Magnetization of Ferromagnetic Particles. Journal of Applied Physics, 29, 595-596. http://dx.doi.org/10.1063/1.1723232 